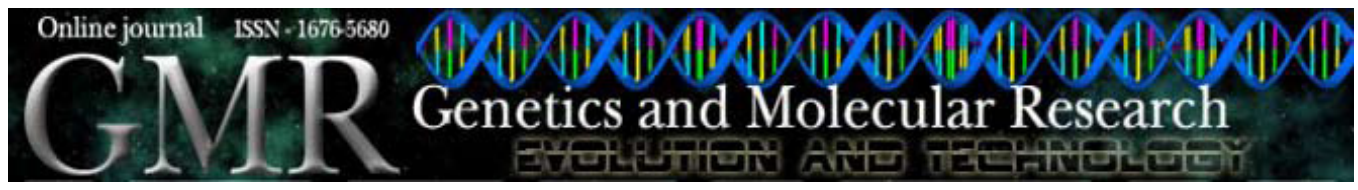

\title{
A single nucleotide polymorphism in the coding region of bovine transferrin is associated with milk fat yield
}

\author{
A. Sanz ${ }^{1}$, L. Ordovás ${ }^{1}$, C. Serrano ${ }^{1}$, P. Zaragoza ${ }^{1}$, J. Altarriba ${ }^{2}$ and \\ C. Rodellar ${ }^{1}$
}

${ }^{1}$ Laboratorio de Genética Bioquímica, Facultad de Veterinaria, Universidad de Zaragoza, Zaragoza, Spain

${ }^{2}$ Grupo de Mejora Genética, Facultad de Veterinaria,

Universidad de Zaragoza, Zaragoza, Spain

Corresponding author: A. Sanz

E-mail: arianne@unizar.es

Genet. Mol. Res. 9 (2): 843-848 (2010)

Received January 13, 2010

Accepted February 8, 2010

Published May 4, 2010

DOI 10.4238/vol9-2gmr784

\begin{abstract}
The bovine transferrin gene $(T F)$ is located at $125 \mathrm{cM}$ on bovine chromosome 1 (BTA1); it codes for transferrin, a glycoprotein that is highly conserved in many species and that is responsible for iron transport. The $T F$ gene has been located in several QTL regions, and some transferrin classes have been associated with fat and milk yields. We analyzed by means of allele-specific oligonucleotide real-time PCR the c.1455A $>$ G SNP in exon 12 of the TF cDNA sequence (accession number U02564), which induces an Asp/Gly substitution at position 469 of the peptide. The c.1455A > G SNP was assayed in eight Spanish cattle breeds, as well as in two groups of Holstein-Friesian animals that had the highest and lowest estimated breeding values for milk fat yield. Analysis of the cSNP showed balanced frequencies in all breeds, with a mean of 0.44. Evaluation of a potential association between the cSNP and the groups of Holstein-Friesian animals selected for milk fat yield showed a significant association $(\mathrm{P}<0.0006)$; the $\mathrm{G}$ allele was associated with high fat production. Significant differences in genotypic frequencies
\end{abstract}


between the groups were also detected $(\mathrm{P}<0.0028)$. These results lead us to suggest that the $T F$ gene has an effect on milk fat yield.

Key words: Bovine; Transferrin; cSNP; Milk fat yield

\section{INTRODUCTION}

Transferrin is a glycoprotein responsible for the transport of iron from sites of absorption and heme degradation to those of storage and utilization by binding two $\mathrm{Fe}^{3+}$ ions in association with the binding of an anion, usually carbonate. It is expressed by the liver and secreted into plasma.

Bovine transferrin is encoded by the transferrin gene $(T F)$, which is located on bovine chromosome 1 (Kappes et al., 1997) and has been physically mapped to conserved chromosomes in different species: HAS 3q21, OAR 1q42-q45, ECA 16, SSC 13q3-1, and BTA 1q41-q46 (Chowdhary et al., 1998). Transferrins have a substantial degree of conservation in amino acid sequence (>70\%); thus, they are predicted to have a very similar overall tertiary structure (Retzer et al., 1996).

It is highly polymorphic in many species, and 10 variants have been detected in cattle, where the major variants described are $\mathrm{A}, \mathrm{D}_{1}, \mathrm{D}_{2}$, and $\mathrm{E}$ (Gahne et al., 1977). The c.1455A>G single nucleotide polymorphism (SNP) in exon 12 of the TF cDNA sequence (accession number U02564) allows us to distinguish the principal variants as two groups by the Asp/Gly substitution at position 469 of the peptide, which induces a change in peptide charge (Laurent and Rodellar, 2001). The presence of an association of the genotypic transferrin classes with fat and milk yield was reported many years ago (Brum et al., 1968).

The interest in the detection and characterization of markers associated with fat and milk production traits has increased in recent years, and there are numerous studies that have focused on this topic (Bagnato et al., 2008; Milanesi et al., 2008). The TF gene is located at $125 \mathrm{cM}$ (centimorgan) on chromosome 1; suggestive quantitative trait loci (QTL) have been detected for fat yield at $50 \mathrm{cM}$, for retail product yield at $53 \mathrm{cM}$, and for USDA yield grade at $63 \mathrm{cM}$ (Casas et al., 2004). However, the location of this gene is outside the limit of the support interval of the QTL on this chromosome (Casas and Stone, 2006). In addition, the transferrin gene is posted in four QTL (birth weight, adjusted weaning weight, adjusted yearling weight, and adjusted fat) called the Bovine QTL Viewer (Polineni et al., 2006).

Because of the role of the $T F$ gene and his placement in a region where several QTLs have been detected, we tested the c.1455A $>$ G SNP in exon 12 of the TF cDNA sequence in 8 Spanish cattle breeds, and we analyzed its potential association with milk fat yield in dairy cattle.

\section{MATERIAL AND METHODS}

\section{DNA samples}

DNA was obtained from two groups of samples. The first was used to study the polymorphism in a total of 193 samples belonging to 8 Spanish cattle breeds: Asturiana de los Valles, $\mathrm{N}=23$; Frisona, $\mathrm{N}=23$; Menorquina, $\mathrm{N}=23$; Limousine, $\mathrm{N}=23$; Monchina, $\mathrm{N}=23$; Serrana Negra de Teruel, $\mathrm{N}=23$; Parda de Montaña, $\mathrm{N}=25$, and Pirenaica, $\mathrm{N}=30$.

The second was used to evaluate the potential association with milk fat yield. This group 
consisted of 211 Holstein-Friesian animals with the highest estimated breeding value (EBV) [N $=117, \mathrm{EBV}=45.19$, reliability $=54 \%]$ and the lowest $\mathrm{EBV}[\mathrm{N}=94, \mathrm{EBV}=-24.45$, reliability $=$ $58 \%$ ] for milk fat yield. EBV for milk fat yield were evaluated by the National Confederation of the Spanish Holstein-Friesian Associations (CONAFE). These animals were selected from 7631 cows from connected herds located in Aragon (a region in the northeast of Spain), with an EBV reliability $>47 \%$. Each tail was constituted by the $1 \%$ of the population with the animals having the most extreme EBV. Table 1 shows the genetic parameters for milk fat yield of the whole Aragon Holstein-Friesian animals and the selected animals for high and low tails

\begin{tabular}{|c|c|c|c|c|}
\hline Population & Mean & SD & Maximum & Minimum \\
\hline Aragon Holstein-Friesian $(\mathrm{N}=7631)$ & 13.67 & 14.58 & 63 & -53 \\
\hline High and low tail $(\mathrm{N}=211)$ & 14.17 & 35.35 & 63 & -53 \\
\hline High tail $(\mathrm{N}=117)$ & 45.19 & 5.53 & 63 & 39 \\
\hline Low tail $(\mathrm{N}=94)$ & -24.45 & 8.08 & -17 & -53 \\
\hline
\end{tabular}

\section{SNP genotyping by allele-specific oligonucleotide RT-PCR}

The genotyping process of c. $1455 \mathrm{~A}>\mathrm{G}$ SNP in exon 12 of the TF cDNA sequence (accession number U02564) was developed by allele-specific oligonucleotide real-time polymerase chain reaction (RT-PCR). A forward primer and two reverse primers containing an intentional mismatch at 3 ' end position to improve specificity were designed using the Primer Express software (Applied Biosystems) and the bovine TF cDNA sequence (GenBank accession number U02564). The oligonucleotide sequences and the positions in the reported sequence are described in Table 2. The reactions were carried out using the SYBR green methodology. A 84-bp fragment was amplified from $50 \mathrm{ng}$ DNA in a total volume of $10 \mu \mathrm{L}$ of reaction mixture containing $0.3 \mu \mathrm{M}$ of each primer and a final $1 \mathrm{X}$ concentration of Master Mix SYBR Green 2X. Preheating of the mixture at $95^{\circ} \mathrm{C}$ for $10 \mathrm{~min}$ was followed by 40 cycles of $15 \mathrm{~s}$ at $95^{\circ} \mathrm{C}$ and $30 \mathrm{~s}$ at $63^{\circ} \mathrm{C}$ on an RT-PCR ABI 7000 (Applied Biosystems). Genotypes were determined by reading the final fluorescence, where a delay of around six cycles allowed the determination of each allele (Germer et al., 2000). Controls were validated by sequencing.

Table 2. Set of primers used for genotyping assay.
\begin{tabular}{lllr}
\hline Primer & Sense & Primer sequence (5' $\rightarrow$ ') & Nucleotide position within U02564 \\
\hline C1_TF_F & Forward & GGGTATCTTGCTGTAGCTGTGG & $1391-1412$ \\
C1_TF_R2 & Reverse & CAGTGTGGCATGACTTCTTGT & $1455-1475$ \\
C1_TF_R1 & Reverse & AGTGTGGCATGACTTCTTGC & $1455-1474$ \\
\hline
\end{tabular}

\section{Data analysis}

Allele and genotype frequencies were calculated by direct counting in all groups of samples. In the analysis of the potential association with milk fat yield in Holstein-Friesian animals, comparisons of the allele and genotype frequencies were tested using binomial con- 
trast of proportions by the $\chi^{2}$ test. The type I error P value was calculated using standard statistical procedures.

\section{RESULTS AND DISCUSSION}

Allelic frequencies of c. $1455 \mathrm{G}>\mathrm{A}$ SNP were estimated in animals from 8 Spanish cattle breeds (Asturiana de los Valles, Frisona, Menorquina, Limousine, Monchina, Serrana Negra de Teruel, Parda de Montaña, and Pirenaica) and in the 2 tails of Holstein-Friesian animals with the highest and lowest EBV for milk fat yield (Figure 1). The 8 Spanish cattle breed showed for the $\mathrm{G}$ allele a minor allele frequency of more than 0.3 with a mean of 0.443 . For animals belonging to the high and low tails, the allelic frequencies were intermediate, being 0.517 for the high tail and 0.351 for the low tail.

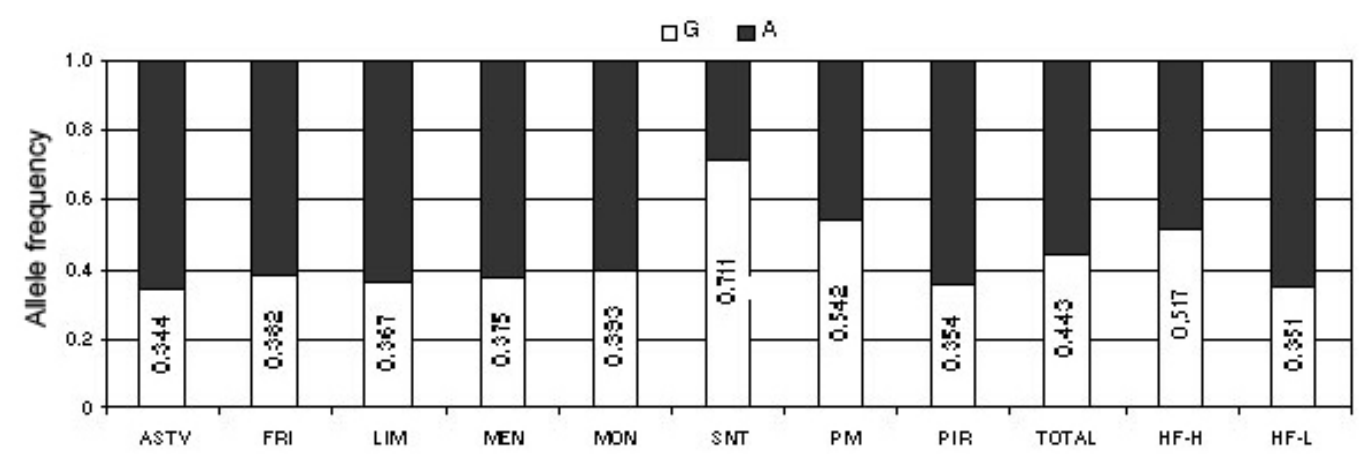

Figure 1. Allele frequencies of c.1455A $>$ G SNP in animals from 8 Spanish cattle breeds and in the two tails of Holstein-Friesian animals with the highest (HF-H) and the lowest (HF-L) estimated breeding value for milk fat yield. Bars correspond to frequencies of $\mathrm{G}$ (white) and A alleles (black); numbers encased correspond to the frequency of the G allele. ASTV = Asturiana de los Valles; FRI = Frisona; LIM = Limousine; MEN = Menorquina; MON = Monchina; SNT $=$ Serrana Negra de Teruel; PM = Parda de Montaña, and PIR = Pirenaica.

The potential association of the c. $1455 \mathrm{~A}>\mathrm{G}$ SNP in exon 12 of the TF cDNA with milk fat yield was evaluated by estimation of the allele frequencies in two tails of HolsteinFriesian animals with extreme EBV for this trait using a binomial contrast of proportions. The analysis of the data obtained showed a significant association $(\mathrm{P}<0.0006)$ between the allelic variants and the tails, where the $\mathrm{G}$ allele was associated with high fat production. Genotypic frequencies were also calculated (Table 3). Differences between genotype frequencies were also significant with a type I error probability of 0.0028 .

Table 3. Genotype frequencies of c. $1455 \mathrm{~A}>\mathrm{G}$ SNP in two tails of Holstein-Friesian cows.
\begin{tabular}{lccc}
\hline Tail & AA & AG & GG \\
\hline High fat yield & 0.22 & 0.52 & 0.26 \\
Low fat yield & 0.42 & 0.46 & 0.12 \\
\hline
\end{tabular}

This polymorphism, as described above, produces an Asp/Gly substitution at position 469 of the peptide, inducing a change in peptide charge (Laurent and Rodellar, 2001). 
Although the transferrin gene is posted in 4 QTL (birth weight, adjusted weaning weight, adjusted yearling weight, and adjusted fat) named as Bovine QTL Viewer (http:// genomes.sapac.edu.au/bovineqtl/), the influence in milk fat yield has not been proved. Nevertheless, there are studies reporting the presence of an association of the genotypic transferrin classes with fat and milk yield (Brum et al., 1968). On the other hand, a relative explanation of this influence could be attributed to the lipolytic activity of transferrin by the Fenton reaction (Rumberger et al., 2004; Green et al., 2006).

In conclusion, we analyzed the cSNP in several Spanish populations and investigated its association with fat yield trait in a group of animals selected by the CONAFE. Our results provide evidence that the $T F$ gene may have a potential effect on milk fat yield traits.

The allelic frequencies obtained in all breeds support this SNP as a potential candidate to be included in any SNP panel for use in an identification or traceability study due to their high variability, and this putative influence on QTL gives an additional value in bovine genetic selection programs.

\section{ACKNOWLEDGMENTS}

Research supported by the Ministerio de Educación y Ciencia (Project \#AGL200605762), Spain. The authors thank Robres Fuertes S.C., Tauste Ganadera, Granja San José and José Berges for providing the samples. We thank Javier Aparicio (APPLA) for providing EBV information.

\section{REFERENCES}

Bagnato A, Schiavini F, Rossoni A, Maltecca C, et al. (2008). Quantitative trait loci affecting milk yield and protein percentage in a three-country Brown Swiss population. J. Dairy Sci. 91: 767-783.

Brum EW, Rausch WH, Hines HC and Ludwick TM (1968). Association between milk and blood polymorphism types and lactation traits of Holstein cattle. J. Dairy Sci. 51: 1031-1038.

Casas E and Stone RT (2006). Putative quantitative trait loci associated with the probability of contracting infectious bovine keratoconjunctivitis. J. Anim. Sci. 84: 3180-3184.

Casas E, Keele JW, Shackelford SD, Koohmaraie M, et al. (2004). Identification of quantitative trait loci for growth and carcass composition in cattle. Anim. Genet. 35: 2-6.

Chowdhary BP, Raudsepp T, Fronicke L and Scherthan H (1998). Emerging patterns of comparative genome organization in some mammalian species as revealed by Zoo-FISH. Genome Res. 8: 577-589.

Gahne B, Juneja RK and Grolmus J (1977). Horizontal polyacrylamide gradient gel electrophoresis for the simultaneous phenotyping of transferrin, post-transferrin, albumin and post-albumin in the blood plasma of cattle. Anim. Blood Groups Biochem. Genet. 8: 127-137.

Germer S, Holland MJ and Higuchi R (2000). High-throughput SNP allele-frequency determination in pooled DNA samples by kinetic PCR. Genome Res. 10: 258-266.

Green A, Basile R and Rumberger JM (2006). Transferrin and iron induce insulin resistance of glucose transport in adipocytes. Metabolism 55: 1042-1045.

Kappes SM, Keele JW, Stone RT, McGraw RA, et al. (1997). A second-generation linkage map of the bovine genome. Genome Res. 7: 235-249.

Laurent P and Rodellar C (2001). Characterization of a single nucleotide polymorphism in the coding sequence of the bovine transferrin gene. Mutat. Res. 458: 1-5.

Milanesi E, Negrini R, Schiavini F, Nicoloso L, et al. (2008). Detection of QTL for milk protein percentage in Italian Friesian cattle by AFLP markers and selective genotyping. J. Dairy Res. 75: 430-438.

Polineni P, Aragonda P, Xavier SR, Furuta R, et al. (2006). The bovine QTL viewer: a web accessible database of bovine quantitative trait loci. BMC Bioinformatics 7: 283. 
Retzer MD, Kabani A, Button LL, Yu RH, et al. (1996). Production and characterization of chimeric transferrins for the determination of the binding domains for bacterial transferrin receptors. J. Biol. Chem. 271: 1166-1173.

Rumberger JM, Peters T Jr, Burrington C and Green A (2004). Transferrin and iron contribute to the lipolytic effect of serum in isolated adipocytes. Diabetes 53: 2535-2541. 